\title{
Systematic review of randomized controlled trial quality in pediatric kidney transplantation
}

\author{
Robert J. Brooks • Gail Y. Higgins • Angela C. Webster
}

Received: 9 February 2010 /Revised: 17 May 2010 / Accepted: 7 June 2010 /Published online: 6 August 2010

(C) IPNA 2010

\begin{abstract}
Limited pediatric-specific research can lead to sub-standard evidence for clinical decision making in children. We sought to systematically evaluate the methodological quality and the reporting standards of randomized controlled trials (RCTs) of transplantation trials in children. We included RCTs of kidney transplant recipients that had enrolled at least one child (aged 17 years or less) and that were reported in English language, peer reviewed journals from 2000 onward in the Cochrane Renal Group's specialized register. Trial reports were assessed against the 22 item checklist of the CONsolidated Standards Of Reporting Trials (CONSORT) statement. Twenty-seven RCTs were included. The reporting of the essential components of the methods, results and discussion domains was unsatisfactory. Mean CONSORT criteria score for the pediatric trials was $67 \%$ and $66 \%$ for trials including both adults and children ( $\mathrm{p}$ value for the difference $=1.00$ ). Trial reporting quality in pediatric transplantation trials is not different from trials involving adults. It is evident that the reporting standards of RCTs in
\end{abstract}

R. J. Brooks · A. C. Webster

Sydney Medical School,

University of Sydney,

Sydney, NSW, Australia

G. Y. Higgins • A. C. Webster

Cochrane Renal Group,

Centre for Kidney Research

at the Children's Hospital at Westmead,

Sydney, NSW, Australia

\section{A. C. Webster}

Centre for Transplant and Renal Research,

Westmead Millennium Institute, Westmead Hospital,

Sydney, NSW, Australia

\section{A. C. Webster $(\bowtie)$}

School of Public Health, University of Sydney,

Room 304a, Edward Ford Building A27,

Sydney, NSW 2006, Australia

e-mail: angela.webster@sydney.edu.au both adult and pediatric transplantation require major improvements. This work bench-marks current standards for future quality improvement.

Keywords CONSORT · Kidney transplantation · Randomized trials $\cdot$ Reporting quality Pediatrics

\section{Introduction}

End-stage kidney disease (ESKD) is a chronic, devastating illness in children with an incident rate of approximately 8 cases per million of the population in Australia [1]. Kidney transplantation is the first-line treatment for ESKD in children $[2,3]$. Treatment guidelines for children receiving kidney transplants rely heavily on empirical evidence derived from studies in adults as a result of the under-representation of children in randomized controlled trials (RCT) throughout the medical literature $[4,5]$. The paucity of pediatric-specific research is multifactorial, but translates into sub-par evidence for clinical decision-making in the treatment of children with ESKD. It is therefore of the utmost importance that pediatric research that has been done or will be undertaken has both the best design and transparent reporting as these elements are fundamental to clinical research.

Although there is a correlation between poorly designed RCTs and poor trial reporting, it has been widely recognized that poor reporting quality alone can lead to exaggeration of treatment efficacy, and that deficiencies in reporting trials are unfortunately very common even in well-designed clinical trials in prominent medical journals $[6,7]$. In response to the substantial gap in the optimal reporting of RCTs, the CONSORT (CONsolidated Standards Of Reporting Trials) statement was developed by two international, multidisciplinary work groups to re-establish robust reporting standards as the foundation for reliable, evidenced-based research [8]. Verification of improvement in the quality of 
reporting with implementation of the CONSORT statement was followed by its widespread endorsement by leading medical journals and the completion of internal audits in several medical disciplines $[9,10]$.

Measurement of the reporting quality of pediatric trials to date has been limited to a few studies completed in psychology, dentistry, complementary medicine, and cerebral palsy physiotherapy [11-14]. Although no studies have examined the quality of reporting in pediatric renal transplantation, trials in adults investigating immunosuppressive interventions for kidney transplant recipients have demonstrated failings in trial reporting, with clinicians expressing that poor reporting quality contributed to difficulty in establishing best practice despite a substantial body of literature in this field $[15,16]$.

In this review, we aimed to evaluate the quality of reporting of transplantation trials in children published in contemporary biomedical literature. By measuring and describing the standard of reporting, we aimed to highlight what has been reported well, and what has been under-reported, to provide a bench-mark against which future improvement in reporting standards can be measured. Furthermore, we aimed to explore any potential differences in reporting standards among trials involving only children and trials involving a mixed population of adults and children.

\section{Materials and methods}

\section{Review design}

All RCTs and quasi-randomized trials (where allocation was not truly random, but based on day of week or patient record number or similar) in kidney transplant recipients that had enrolled at least one child (defined as age 17 or less), and that were reported from 2000 onwards were eligible for inclusion in the review. These trials could involve either children alone (referred to in this paper as pediatric trials), or mixed populations of adults and children (referred to in this paper as mixed population trials). Trials enrolling only adult participants (18 years and over) were excluded, as were trials in which recipients had received another solid organ in addition to kidney transplantation. We included only reports of trials published in peer-reviewed biomedical literature, and excluded trials reported only as abstracts from conference proceedings or in non-peer-reviewed journals. NonEnglish language publications were excluded because of a lack of feasibility as there were no resources available for translation. There were no other exclusions.

Identification of cohort of trials for inclusion

Relevant trials were obtained from the Cochrane Renal Group's specialized register of RCTs (2000 to 30 April 2008). The search was designed to retrieve contemporary reports of RCTs published since CONSORT reporting standards became widely accepted, and so did not include reports prior to this century. The search strategy was developed in collaboration with the Cochrane Renal Group's trial search coordinators, and included trials assigned the keyword "Child", OR trials assigned any or all of the medical subject heading (MeSH) terms "adolescence", "adolescent", "child", or "infant". Transplantation trials were further separated from trials investigating general renal medical conditions, chronic kidney disease, peritoneal dialysis or hemodialysis by a subset search strategy using text words (transplant*), (donor*), (graft*), or (recipient*). Where necessary, we reviewed the full citations to clarify all trial reports meeting the inclusion criteria. A second reviewer (AW) independently reviewed the search results and discrepancies were resolved by discussion. In the event of identification of multiple reports from the same trial, only the earliest publication reporting fullest clinical results was selected, and subsequent reports were discarded. In doing this, we reasoned that the first report of any trial to enter the public domain might be expected to report methods clearly and unambiguously.

\section{Assessment tool}

The revised CONSORT statement was used as a basis for assessing reporting quality. CONSORT is a validated, evidence-based guideline demonstrated to improve the quality of reporting of RCTs, which has been endorsed by the International Committee of Medical Journal Editors, and by over 343 medical journals including the New England Journal of Medicine and The Lancet, as well as the leading nephrology and transplantation journals (such as the Journal of the American Society of Nephrology, the American Journal of Transplantation and Transplantation) (Fig. 1) $[8,9,17]$.

\section{Data abstraction and analysis}

Data abstraction was completed by a single reviewer (RB) not blinded to trial authors or journal, with any uncertainties discussed with a second reviewer (AW) using a standardized data form to document trial characteristics and the presence or absence of CONSORT checklist items. The reporting quality of included trials was assessed using the 22-item CONSORT checklist (Fig. 1), with the successful reporting of a CONSORT criteria item only awarded if all of the required components detailed in the CONSORT statement were completely satisfied [8]. Characteristics of each included trial were summarized descriptively, and quantitative frequencies for each individual item and overall trial CONSORT scores were tabulated. Comparisons of the reporting quality of CONSORT items were analyzed as binary variables (did not meet CONSORT requirement/did 
Fig. 1 The 2001 revised CONSORT statement checklist of essential items that should be included in reports of randomized controlled trials (RCTs). This checklist was used to score reports of transplantation trials including children in this review

\section{Topic} Item Descriptor

\begin{tabular}{|c|c|c|}
\hline \multicolumn{3}{|l|}{ INTRODUCTION } \\
\hline Background & 2 & Scientific background and explanation of rationale. \\
\hline \multicolumn{3}{|l|}{ METHODS } \\
\hline Participants & 3 & $\begin{array}{l}\text { Eligibility criteria for participants and the settings and locations where } \\
\text { the data were collected. }\end{array}$ \\
\hline Interventions & 4 & $\begin{array}{l}\text { Precise details of the interventions intended for each group and how/ } \\
\text { when they were administered. }\end{array}$ \\
\hline Objectives & 5 & Specific objectives and hypotheses. \\
\hline Outcomes & 6 & Clearly defined primary and secondary outcome measures. \\
\hline Sample size & 7 & $\begin{array}{l}\text { How sample size was determined and explanation of any interim } \\
\text { analyses and stopping rules. }\end{array}$ \\
\hline Sequence generation & 8 & $\begin{array}{l}\text { Method used to generate the random allocation sequence; including } \\
\text { details of any restrictions. }\end{array}$ \\
\hline Allocation concealment & 9 & Method used to implement the random allocation sequence. \\
\hline Implementation & 10 & $\begin{array}{l}\text { Who generated the allocation sequence, enrolled participants, and } \\
\text { assigned participants to their groups. }\end{array}$ \\
\hline Blinding (masking) & 11 & $\begin{array}{l}\text { Whether participants, study personnel, and data analysts were blinded to } \\
\text { group assignment. }\end{array}$ \\
\hline Statistical methods & 12 & $\begin{array}{l}\text { Statistical methods used to compare groups for primary outcome(s); } \\
\text { methods for additional analyses. }\end{array}$ \\
\hline \multicolumn{3}{|l|}{ RESULTS } \\
\hline Participant flow & 13 & $\begin{array}{l}\text { Flow of participants through each stage including the numbers of } \\
\text { participants randomly assigned, receiving intended treatment, } \\
\text { completing the protocol, and analyzed for the primary outcome. }\end{array}$ \\
\hline Recruitment & 14 & Dates defining the periods of recruitment and follow-up. \\
\hline Baseline data & 15 & Baseline demographic and clinical characteristics of each group. \\
\hline Numbers analyzed & 16 & $\begin{array}{l}\text { Number of participants in each group included in each analysis and } \\
\text { whether the analysis was by "intention-to-treat". State the results in } \\
\text { absolute numbers when feasible. }\end{array}$ \\
\hline Outcomes \& estimation & 17 & $\begin{array}{l}\text { For each outcome, a summary of results for each group, the estimated } \\
\text { effect size and its precision. }\end{array}$ \\
\hline Ancillary analyses & 18 & $\begin{array}{l}\text { Address multiplicity by reporting other analyses performed; indicating } \\
\text { those pre-specified/exploratory. }\end{array}$ \\
\hline Adverse events & 19 & All important adverse events or side effects in each intervention group. \\
\hline \multicolumn{3}{|l|}{ DISCUSSION } \\
\hline Interpretation & 20 & $\begin{array}{l}\text { Interpretation of the results; including study hypotheses, sources of } \\
\text { potential bias or imprecision. }\end{array}$ \\
\hline Generalizability & 21 & Generalizability (external validity) of the trial findings. \\
\hline Overall evidence & 22 & General interpretation of the results in the context of current evidence. \\
\hline
\end{tabular}

meet CONSORT requirement) using a two-tailed Fisher's exact test. Overall CONSORT score in pediatric trials versus mixed population trials was analyzed using the two-tailed non-parametric Mann-Whitney $U$ test. A value of $P<0.05$ was considered significant.

\section{Results}

A total of 1,775 abstracts were identified by the initial search strategy. A full paper review was undertaken for 161 trials that could not be excluded on title and abstract 
Fig. 2 Identification of reports of randomized controlled trials for inclusion in the systematic review of the quality of reporting of transplantation trials in children. Criteria for inclusion: all randomized controlled trials of kidney transplant recipients, reported in peer reviewed journals, from 2000 onwards, in the English language, conducted either exclusively in children, or including children within a mixed population of child and adult participants

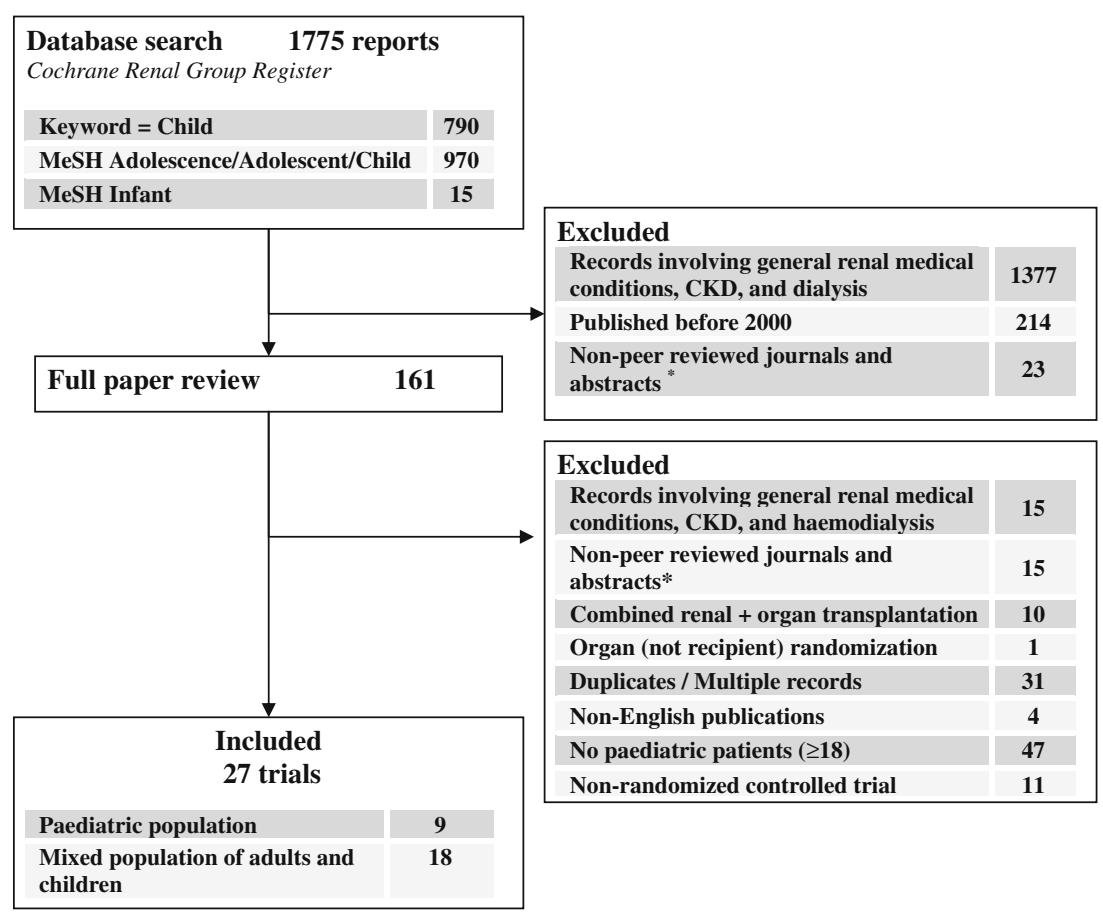

* Reports of trials excluded if reported only as abstracts from conference proceedings, or if reported in non-peer reviewed journals such as Transplantation Proceedings alone, and 27 were identified as meeting the inclusion criteria (Fig. 2). The 27 trials included comprised a total of 6,082 randomized participants; 928 participants in pediatric trials and 5,154 participants in mixed population trials containing both adults and children. For the mixed population trials it was not always clear exactly how many children were included, of the total randomized participants. The 27 trials included were reported in 12 different journals. The characteristics of the trials included are summarized in Table 1.

CONSORT items: title, abstract, and introduction

Only 4 out of $9(44 \%)$ pediatric trials and 10 out of 18 $(56 \%)$ mixed population trials described the trial as randomized in the title of the publication, but all the trials included appropriately described the fact that participants were randomly allocated to interventions in the trial abstracts (Table 2).

\section{CONSORT items: methods}

With the exception of the excellent reporting of specific objectives and hypotheses (27 out of 27) and the statistical methods for planned analyses (26 out of 27 ), the essential components of a well-reported methods section were absent from many of the trials (Table 2). Clearly defined trial eligibility criteria and sufficient information on data collection settings were not reported in one-third of the papers.
Precise details of the interventions intended for each group and how and when they were received was reported in $78 \%$ of the trials included ( 7 out of 9 pediatric trials, 14 out of 18 mixed population trials). Sample size calculation was poorly reported with only 4 pediatric trials $(44 \%)$ and 9 mixed population trials $(50 \%)$ mentioning this information. Randomization reporting was unsatisfactory as many trials failed to include detailed descriptions of the methods used to generate the random allocation sequence (10 out of 27), to implement allocation concealment (9 out of 27), and to separate creation of the allocation sequence from assignment to the study groups ( 8 out of 27). Pediatric trials reported these randomization details marginally better than mixed population trials $(44 \%, 56 \%$, and $44 \%$ respectively compared with $33 \%, 22 \%$, and $22 \%$ respectively), but the difference was not statistically significant. Blinding of participants, intervention administrators, and outcome assessors was under-reported. In particular, understanding who was blinded to treatment intervention was frequently unclear. Thirteen trials (48\%) were clearly identified as open-label studies. For the remaining trials, only 2 mixed population trials $(7 \%)$ provided complete details on blinding. Five trials (19\%) reported partial information whereby at least one of the participants, administrators, or assessors was specifically reported as blinded. Three trials (11\%) gave no other information beyond stating that the trial was either "double-blinded" or "blinded." There was no statistical difference $(P>0.05)$ in the quality of reporting for any methodological items between pediatric and mixed population trials. 
Table 1 Characteristics of trial reports included in review, stratified into those conducted exclusively in children, and those in mixed populations of both adults and children ${ }^{\mathrm{a}}$

\begin{tabular}{|c|c|c|c|c|c|c|c|c|c|}
\hline \multirow[t]{2}{*}{ Reference } & \multicolumn{2}{|l|}{ Setting } & \multicolumn{4}{|c|}{ Participants } & \multirow[t]{2}{*}{ Intervention rationale } & \multirow{2}{*}{$\begin{array}{l}\text { Main } \\
\text { outcome }\end{array}$} & \multirow{2}{*}{$\begin{array}{l}\text { Declaration of } \\
\text { pharmaceutical } \\
\text { sponsorship }\end{array}$} \\
\hline & Site & Country/Region ${ }^{\mathrm{b}}$ & $N$ & Population & $\begin{array}{l}\text { Age }^{\mathrm{a}} \\
\text { Mean (SD) }\end{array}$ & Range & & & \\
\hline [18] & Multi & $\mathrm{AR}$ & 27 & Children & $8.9(0.6)$ & $\leq 16$ & Steroid formulation & Bone metabolism & Yes \\
\hline [19] & Multi & CA, US & 68 & Children & ns & $\leq 16$ & Hormone therapy & Growth & No \\
\hline [20] & Single & US & 23 & Children & ns & $\leq 16$ & Hormone therapy & Bone metabolism & Yes \\
\hline [21] & Multi & EU & 204 & Children & $\mathrm{ns}$ & $\leq 18$ & Immunosuppression & Acute rejection & Yes \\
\hline [22] & Single & ns & 60 & Children & $13.2(4.3)$ & $\leq 17$ & Calcium replacement & Bone metabolism & No \\
\hline [23] & Multi & US & 287 & Children & ns & $\mathrm{ns}$ & Immunosuppression & Graft survival & No \\
\hline [24] & Multi & EU & 192 & Children & ns & $\leq 18$ & Immunosuppression & Acute rejection & Yes \\
\hline [25] & Single & US & 23 & Children & $14.6(3.7)$ & ns & Self-care technique & Gingival over-growth & Yes \\
\hline [26] & Multi & NL & 44 & Children & $11.9(\mathrm{~ns})$ & ns & Immunosuppression & Graft function & No \\
\hline [27] & Multi & CA, US & 223 & Mixed & $46.5(12.4)$ & $12+$ & Immunosuppression & Composite efficacy & Yes \\
\hline [28] & Multi & US & 719 & Mixed & $44.9(13.6)$ & $13+$ & Immunosuppression & Acute rejection & Yes \\
\hline [29] & Multi & EU, US & 616 & Mixed & $40.3(\mathrm{~ns})$ & $15-76$ & Anti-viral therapy & Economic analysis & Yes \\
\hline [30] & Single & ns & 82 & Mixed & $31.2(\mathrm{~ns})$ & $4-56$ & Biopsy technique & Biopsy adequacy & No \\
\hline [31] & Single & US & 104 & Mixed & 49 (ns) & $16-76$ & Immunosuppression & Acute rejection & Yes \\
\hline [32] & Multi & $\mathrm{AU}, \mathrm{CA}, \mathrm{EU}$ & 525 & Mixed & 48.8 (ns) & $16-73$ & Immunosuppression & Graft survival & Yes \\
\hline [33] & Multi & CA, EU, US & 103 & Mixed & $43.6(10.7)$ & $16-65$ & Immunosuppression & Acute rejection & Yes \\
\hline [34] & Multi & AU, CA, EU, US & 576 & Mixed & $45.6(12.7)$ & $15-71$ & Immunosuppression & Acute rejection & Yes \\
\hline [35] & Multi & ns & 354 & Mixed & ns & $16-70$ & Immunosuppression & Graft survival & Yes \\
\hline [36] & Single & IT & 11 & Mixed & $15.9(3.4)$ & $11-22$ & Diet supplementation & Nutrition biomarkers & No \\
\hline [37] & Multi & $\mathrm{CN}$ & 114 & Mixed & $42.2(10.6)$ & $14-72$ & Pharmacokinetics & Economic analysis & Yes \\
\hline [38] & Multi & ns & 150 & Mixed & $44(16)$ & $14-78$ & Immunosuppression & Acute rejection & Yes \\
\hline [39] & Single & EG & 70 & Mixed & $28(12)$ & $16-45$ & Pharmacokinetics & Economic analysis & No \\
\hline [40] & Single & $\mathrm{BR}$ & 70 & Mixed & $34.8(10.6)$ & $13+$ & Immunosuppression & Acute rejection & Yes \\
\hline [41] & Multi & ns & 111 & Mixed & 45.9 (11.9) & $16-65$ & Immunosuppression & Composite efficacy & No \\
\hline [42] & Multi & $\mathrm{AR}, \mathrm{BR}, \mathrm{CA}, \mathrm{US}$ & 583 & Mixed & $43.3(\mathrm{~ns})$ & $16-71$ & Immunosuppression & Composite efficacy & Yes \\
\hline [43] & Single & ns & 75 & Mixed & 34.7 (11.9) & $7-67$ & Surgical technique & Graft function & No \\
\hline [44] & Multi & $\mathrm{BR}, \mathrm{CA}, \mathrm{US}$ & 668 & Mixed & $47.8(13)$ & $17-74$ & Immunosuppression & Composite efficacy & Yes \\
\hline
\end{tabular}

$\mathrm{ns}=$ items not reported in the original publication documented as "not stated"

${ }^{\text {a }}$ There may be other important descriptive data reported at trial level that we have not included in this table, including different measures of the age of trial participants, and we direct readers to the citations for further clarification

${ }^{\mathrm{b}}$ Country or region where research was conducted as reported according to the International Organization for Standardization (ISO) two-letter region code: $\mathrm{AR}=$ Argentina, $\mathrm{AU}=$ Australia, $\mathrm{BR}=$ Brazil $, \mathrm{CA}=\mathrm{Canada}, \mathrm{CN}=$ China $, \mathrm{EG}=\mathrm{Egypt}, \mathrm{EU}=$ multiple countries of the European Union, $\mathrm{IT}=\mathrm{Italy}, \mathrm{NL}=$ The Netherlands, US = United States of America

\section{CONSORT items: results}

Although the flow of participants through each stage of the study was reported in 8 of the pediatric trials $(89 \%)$ and 12 of the mixed population trials $(67 \%)$, only 6 trials $(22 \%)$ in total made adequate use of the recommended CONSORT flow diagrams, with fewer mixed population trials $(11 \%)$ than pediatric trials (44\%) using these visual flow diagrams (difference not significant $P>0.05$, Table 3 ). When describing the participant analysis set, we found appropriately reported intention-to-treat (ITT) analysis in only 13 trials
(48\%). Furthermore, 5 trials $(28 \%)$ mislabeled their analyses as ITT when they were in fact not examined using a full analysis set. Outcome reporting was extremely poor, with only 9 trials $(33 \%)$ reporting complete details for all trial arms of the intervention summary results, estimated effect size, and precision. Ancillary analyses including exploratory and sub-group analyses were common with one third of trials in total completing analyses not pre-specified in the methods section. There was no statistical difference $(P>0.05)$ in the quality of reporting for any CONSORT results items between pediatric and mixed population trials. 
Table 2 Identification of CONSORT criteria items (1 through 12) presented in the title, abstract, introduction, and methods of the kidney transplantation trials included in the study

\begin{tabular}{|c|c|c|c|c|c|c|}
\hline Item & CONSORT criteria & & $\begin{array}{l}\text { Child }^{\mathrm{b}}(\%) \\
n=9\end{array}$ & $\begin{array}{l}\operatorname{Mixed}_{n}^{\mathrm{b}}(\%) \\
n=18\end{array}$ & $\begin{array}{l}\operatorname{Total}^{\mathrm{c}}(\%) \\
n=27\end{array}$ & $P$ value* \\
\hline \multirow[t]{3}{*}{1} & \multirow[t]{3}{*}{ Title and abstract } & & $9(100)$ & $18(100)$ & $27(100)$ & 1.000 \\
\hline & & Title & $4(44)$ & $10(56)$ & $14(52)$ & 0.695 \\
\hline & & Abstract & $9(100)$ & $18(100)$ & $27(100)$ & 1.000 \\
\hline \multirow[t]{3}{*}{2} & \multirow[t]{3}{*}{ Introduction } & & $9(100)$ & 17 (94) & $26(96)$ & 1.000 \\
\hline & & Scientific background & $9(100)$ & 17 (94) & $26(96)$ & 1.000 \\
\hline & & Explanation of rationale & $9(100)$ & $17(94)$ & $26(96)$ & 1.000 \\
\hline 3 & Participants & & $6(67)$ & $12(67)$ & $18(67)$ & 1.000 \\
\hline 4 & Interventions & & $7(78)$ & $14(78)$ & $21(78)$ & 1.000 \\
\hline 5 & Objectives & & $9(100)$ & $18(100)$ & $27(100)$ & 1.000 \\
\hline 6 & Outcomes & & $7(78)$ & $11(61)$ & $18(67)$ & 0.667 \\
\hline 7 & Sample size & & $4(44)$ & $9(50)$ & $13(48)$ & 1.000 \\
\hline 8 & Randomization sequence generation & & $4(44)$ & $6(33)$ & $10(37)$ & 0.683 \\
\hline 9 & Randomization allocation concealment & & $5(56)$ & $4(22)$ & $9(33)$ & 0.108 \\
\hline 10 & Randomization implementation & & $4(44)$ & $4(22)$ & $8(30)$ & 0.375 \\
\hline \multirow[t]{5}{*}{11} & \multirow[t]{5}{*}{ Blinding } & Complete reporting & $0(0)$ & $2(11)$ & $2(7)$ & 0.538 \\
\hline & & Partial reporting & $2(22)$ & $3(17)$ & $5(19)$ & 1.000 \\
\hline & & "Double blind"; "blinded"a & $1(11)$ & $2(11)$ & $3(11)$ & 1.000 \\
\hline & & Insufficient reporting & $3(33)$ & $1(6)$ & $4(15)$ & 0.093 \\
\hline & & Open label study & $3(33)$ & $10(56)$ & $13(48)$ & 0.420 \\
\hline 12 & Statistical methods & & $9(100)$ & $17(94)$ & $26(96)$ & 1.000 \\
\hline
\end{tabular}

* $P$ value for difference between child and mixed population trials, calculated using Fisher's exact test

a No elaboration of blinding provided; trial was described only as either "double blind" or "blinded"

${ }^{\mathrm{b}}$ Pediatric trials including only children; all participants $\leq 17$ years old. Mixed population of adults and children; at least one participant aged $\leq 17$ years

${ }^{\mathrm{c}}$ Total number of trials including both pediatric and mixed population trials

\section{CONSORT items: discussion}

Reporting of result interpretation was poor with only 10 trials $(37 \%)$ in total clearly discussing both the summary of key findings and the trial limitations (Table 3). Failure to report these items was largely a result of deficiencies in reporting any trial limitations, with only 2 pediatric trials $(22 \%)$ and 8 mixed population trials (44\%) describing this CONSORT item as recommended. All included trials interpreted their results in the context of other current evidence, but 0 pediatric trials and only 3 mixed population trials $(17 \%)$ incorporated a systematic review of current evidence into the discussion section. There was no statistical difference $(P>0.05)$ in the quality of reporting for any of the required CONSORT discussion item components between pediatric and mixed population trials.

\section{Overall CONSORT score}

As demonstrated in Fig. 3, neither pediatric nor mixed population trials scored well overall when compared against the 22 item CONSORT checklist. In fact, one trial scored as low as 8 out of 22 of the CONSORT criteria (36\%) [39]. The difference between the mean CONSORT scores for pediatric trials (14.78) and mixed population trials (14.50) was not statistically significant $(P=0.56$, Mann-Whitney $U$ test).

\section{Discussion}

\section{Summary of main findings}

This systematic review of trial reporting quality in pediatric transplantation trials indicates that it is generally not optimal, and has room for further improvement when evaluated against the established reporting criteria endorsed by the majority of journals that published these reports. None of the trials included completely satisfied the requirements of the CONSORT statement despite all but one of these trials being published in journals that endorse CONSORT (as of May 2009) [39]. Moreover, the trials on average reported absolutely no information for one third of the recommended 22-item CONSORT checklist. In general, while the CONSORT statement requirements for 
Table 3 Identification of CONSORT criteria items (13 through 22) presented in the results and discussion sections of the kidney transplantation trials included in the study

\begin{tabular}{|c|c|c|c|c|c|c|}
\hline Item & CONSORT criteria & & $\begin{array}{l}\text { Child }^{\mathrm{a}}(\%) \\
n=9\end{array}$ & $\begin{array}{l}\operatorname{Mixed}_{n=18}^{\mathrm{a}}(\%) \\
\end{array}$ & $\begin{array}{l}\operatorname{Total}^{\mathrm{b}}(\%) \\
n=27\end{array}$ & $P$ value* \\
\hline \multirow[t]{2}{*}{13} & \multirow[t]{2}{*}{ Participant flow } & & $8(89)$ & $12(67)$ & $20(74)$ & 0.363 \\
\hline & & Flow diagram & $4(44)$ & $2(11)$ & $6(22)$ & 0.136 \\
\hline 14 & Recruitment & & $4(44)$ & $13(72)$ & $17(63)$ & 0.219 \\
\hline 15 & Baseline data & & $7(78)$ & $16(89)$ & $23(85)$ & 0.582 \\
\hline \multirow[t]{4}{*}{16} & \multirow[t]{4}{*}{ Numbers analyzed } & & $8(89)$ & $15(83)$ & $23(85)$ & 1.000 \\
\hline & & Intention-to-treat & $3(33)$ & $10(56)$ & $13(48)$ & 0.420 \\
\hline & & Pseudo-ITT & $2(22)$ & $3(17)$ & $5(19)$ & 1.000 \\
\hline & & ITT not reported & $4(44)$ & $5(28)$ & $9(33)$ & 0.423 \\
\hline 17 & Outcomes & & $3(33)$ & $6(33)$ & $9(33)$ & 1.000 \\
\hline \multirow[t]{2}{*}{18} & \multirow[t]{2}{*}{ Ancillary analyses } & Pre-specified & $6(67)$ & $12(67)$ & $18(67)$ & 1.000 \\
\hline & & Not pre-specified & $3(33)$ & $6(33)$ & $9(33)$ & 1.000 \\
\hline 19 & Adverse events & & $6(67)$ & $15(83)$ & $21(78)$ & 0.367 \\
\hline \multirow[t]{3}{*}{20} & \multirow[t]{3}{*}{ Interpretation } & & $2(22)$ & $8(44)$ & $10(37)$ & 0.406 \\
\hline & & Summary of key findings & $8(89)$ & $18(100)$ & $26(96)$ & 0.333 \\
\hline & & Discussion of limitations & $2(22)$ & $8(44)$ & $10(37)$ & 0.420 \\
\hline 21 & Generalizability & & $7(78)$ & $12(67)$ & $19(70)$ & 0.676 \\
\hline \multirow[t]{2}{*}{22} & Overall evidence & & $9(100)$ & $18(100)$ & $27(100)$ & 1.000 \\
\hline & & Systematic review & $0(0)$ & $3(17)$ & $3(11)$ & 0.529 \\
\hline
\end{tabular}

* $P$ for the difference between child and mixed population trials, calculated using Fisher's exact test

${ }^{a}$ Pediatric trials including only children; all participants $\leq 17$ years old. Mixed population of adults and children; at least one participant aged $\leq 17$ years

${ }^{\mathrm{b}}$ Total number of trials including both pediatric and mixed population trials

titles, abstracts, and introductions were well reported, the reporting of essential components of the methods, results and discussion domains was unsatisfactory.

This review identified no evidence of discrepancy between the quality of reporting of trials that included only children compared with trials in which children were a subset of patients in an otherwise adult study. Trials including children alone were no better or no worse than those that included both children and adults, with no statistical difference identified between the reporting quality in any of the 22 required CONSORT items, nor any significant difference $(P=0.56)$ in the overall average CONSORT criteria scores. We acknowledge that the sample size of our trial cohort was small, but nevertheless, this suggests that sub-optimal reporting of trials might be a widespread problem, and that report standards of RCTs in both adult and pediatric transplantation require major improvement [16].

\section{Findings in context}

To our knowledge this is the first systematic review of the reporting quality of RCTs in the pediatric transplantation population, but is among a small but growing number of studies assessing reporting standards in the broader pediatric literature [11-14]. Other studies in reporting quality in pediatric research to date have been limited to other fields and specialist areas and findings from these studies have unfortunately been equally unimpressive, showing similar deficiencies in reporting standards. Despite our findings in the transplantation trials, the results of our study compare favorably with those of the other pediatric settings. We demonstrated that the reporting of pediatric transplantation trials met an average of $67 \%$ of the CONSORT criteria for trials including only children and $66 \%$ for trials including a mixed population of adults and children. In contrast, only $40 \%$ of the CONSORT criteria items in complementary medicine reports in children and $47 \%$ of the CONSORT criteria items in reports in cerebral palsy physiotherapy were well reported $[13,14]$. Another study in pediatric psychology found that half of CONSORT items were reported less than $25 \%$ of the time [11]. Although this is not the first time that many of these reporting deficiencies have been identified in the broader literature, our findings provide a somber summary of the quality of the reports of trials available to inform treatment choices in pediatrics.

Strengths and weaknesses

Our systematic review identified and summarized all available trials from the Cochrane Renal Group's spe- 
Fig. 3 Quality of reporting of included kidney transplantation trials: the percentage of

CONSORT criteria that were completely reported for each pediatric (black) trial and mixed population (gray) trial. Pediatric trials comprised solely children 17 years or younger, and mixed population trials consisted of a mixed population of adults and children in which there must be at least one child aged 17 years or younger. Mean CONSORT criteria score for the pediatric trials was $14.78( \pm 2.68 ; 67 \%)$ and $14.50( \pm 3.94 ; 66 \%)$ for the mixed population trials $(P=0.56$, Mann-Whitney $U$ test $)$

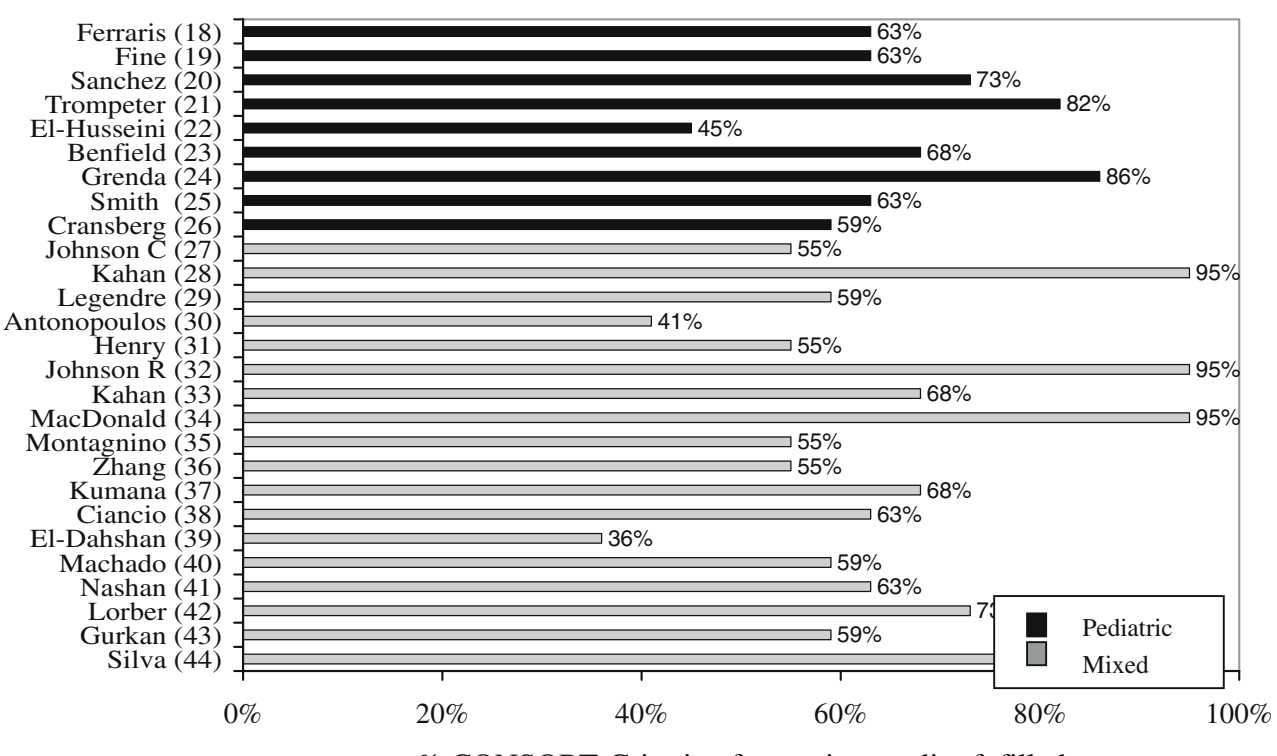

$\%$ CONSORT Criteria of reporting quality fufilled cialized register of RCTs that met our inclusion criteria in an effort to capture the totality of RCT evidence available on kidney transplantation in children. In an effort to maintain a robust methodology, two different reviewers worked independently to identify trials, and in data abstraction agreement was sought with a second reviewer for any data that were in any way ambiguous. However, although there is the intention to be meticulous, this type of research is time-consuming and open to human error, which is not helped by an absence of structured rational reporting in many of the trial reports, and differences in the formatting of manuscripts among different journals [14].

The exclusion of non-English publications has been demonstrated to introduce bias into meta-analyses of interventions. A limitation of our work was to exclude non-English language literature, due to difficulty in obtaining translations of these reports, and it is possible that in this way we have introduced some bias to our findings [45].

In limiting this review to only transplantation trials, we included a relatively small number of trials, and as a result we may have had inadequate power to detect differences in reporting quality between pediatric and mixed populations trials that do exist. In fact, only one third of trials assessed in this review involved transplantation in an exclusively pediatric population. This may also explain why the findings were more comparable to the results of a systematic review of renal transplantation immunosuppression in an adult population (adequate reporting of $69.1 \%$ of the CONSORT criteria) rather than those of other pediatric systematic reviews that had lower overall reporting adequacy [16]. Thus, a larger work examining the totality of RCTs related to pediatric nephrology might be more informative.
Implications for clinical practice and conclusion

Consistent with the literature in other medical disciplines, there is much room for improvement in the reporting of RCTs in children requiring kidney transplantation. Although a multitude of factors contribute to the underrepresentation of children in randomized trials compared with adult-centered research, our findings are the first to suggest that the quality of reporting in pediatric transplantation trials is no worse than that of the adult literature. However, it does suggest that even when children with kidney transplants do take part in an RCT, the results of these trials are not reported as adequately and as transparently as they could be, which is a general failing warranting action.

The evidence supports initiatives such as the CONSORT statement and efforts by the International Committee of Medical Journal Editors to correct reporting deficiencies found throughout the biomedical literature, but more must be done to ensure guidelines are stringently applied to transplantation trials involving children. Endorsement by journals appears to be insufficient alone, and there is evidence that unfamiliarity with the CONSORT criteria by authors and reviewers can contribute to this problem [46].

Responsibility for ensuring that trial reporting is good quality rests with all involved in clinical research, from funders to publishers. Researchers bear responsibility for conducting their research ethically and responsibly, and ensuring that they report details of their work according to best practice, using the appropriate reporting guidelines for their study design, which for an RCT when writing for journals is the CONSORT statement. Peer reviewers are the expert gate-keepers, who as part of peer review bear responsibility for checking research validity, which includes 
assessing study design and reporting, and alerting journal editors where they find this lacking. Ultimate responsibility for reports of RCTs appearing in journals rests with the journal editorial board.

Better training of junior researchers in research methodology might improve the standards of research writing, and peer review. Increasing literacy in trial reporting among trainees, junior researchers, and scientists might be addressed by offering training opportunities as part of postgraduate continuing medical education (CME). Professional societies might endorse this by including trial design and reporting workshops as part of CME education at conferences and scientific meetings.

It is encouraging that there is a movement toward better reporting within the transplant community with CONSORT-derived, transplantation-specific reporting criteria currently being recommended and developed for individual journals $[15,46,47]$. Unfortunately, history has demonstrated that guidelines only benefit the quality of reporting when they are followed.

Acknowledgements We thank Dr. Terry Klassen and Dr. Patricia Caldwell, who gave advice and input to a preliminary version of this work.

Conflicts of interest and funding sources statement None of the authors declare any conflicts of interest in this project. There was no funding for this work. No ethics approval was necessary for this work.

\section{References}

1. McTaggart S, Kennedy S, McDonald S, Henning P, Dent $\mathrm{H}$ (2008) Pediatric report. In: MacDonald S, Excell L, Livingston B (eds) The thirty-first report: Australia and New Zealand Dialysis and Transplant Registry 2008. ANZDATA Registry, Adelaide

2. Milliner D (2004) Pediatric renal-replacement therapy-coming of age. N Engl J Med 350:2637-2639

3. McDonald S, Craig J (2004) Long-term survival of children with end-stage renal disease. N Engl J Med 350:2654-2662

4. Wilson J (1999) An update on the therapeutic orphan. Pediatrics 104:585-590

5. Caldwell P, Murphy S, Butow P, Craig J (2004) Clinical trials in children. Lancet 364:803-811

6. Altman D, Schulz K, Moher D, Egger M, Davidoff F, Elbourne D, Gøtzsche PC, Lang T; CONSORT Group (Consolidated Standards of Reporting Trials) (2001) The revised CONSORT statement for reporting randomized trials: explanation and elaboration. Ann Intern Med 134:663-694

7. Moher D, Pham B, Jones A, Cook DJ, Jadad AR, Moher M, Tugwell P, Klassen TP (1998) Does quality of reports of randomized trials affect estimates of intervention efficacy reported in meta-analyses? Lancet 352:609-613

8. Moher D, Schulz K, Altman D (2001) The CONSORT statement: revised recommendations for improving the quality of reports of parallel-group randomized trials. Lancet 357:1191-1194

9. Moher D, Jones A, Lepage L (2001) Use of the CONSORT statement and quality of reports of randomized trials: a comparative before-and-after evaluation. The CONSORT Group. JAMA 285:1992-1995
10. Kane R, Wang J, Garrard J (2007) Reporting in randomized clinical trials improved after adoption of the CONSORT statement. J Clin Epidemiol 60:241-249

11. Stinson J, McGrath P, Yamada J (2003) Clinical trials in the Journal of Pediatric Psychology: applying the CONSORT statement. J Pediatr Psychol 28:159-167

12. Al-Namankany A, Ashley P, Moles D, Parekh S (2009) Assessment of the quality of reporting randomized clinical trials in pediatric dentistry journals. Int J Paediatr Dent 19:318-324

13. Moher D, Soeken K, Sampson M, Ben-Porat L, Berman B (2002) Assessing the quality of reports of randomized controlled trials in pediatric complementary and alternative medicine. BMC Pediatr 2:2

14. Anttila H, Malmmivaara A, Kunz R, Autti-Ramo L, Makela M (2006) Quality of reporting randomized controlled trials in cerebral palsy. Pediatrics 117:2222-2230

15. Curtis J, Kaplan B (2004) Transplant immunosuppressive drug trials on trial. Am J Transplant 4:671-672

16. Fritsche L, Einecke G, Fleiner F, Dragun D, Neumayer H, Budde K (2004) Reports of large immunosuppression trials in kidney transplantation: room for improvement. Am J Transplant 4:738-743

17. Moher D, Morrison A, Schulz K, Altman DG, Hill C, Gaboury I (2006) Does the CONSORT checklist improve the quality of reports of randomized controlled trials? A systematic review. Med J Aust 185:263-267

18. Ferraris JR, Pasqualini T, Legal S, Sorroche P, Galich AM, Pennisi P, Domene H, Jasper H (2000) Effect of deflazacort versus methylprednisone on growth, body composition, lipid profile, and bone mass after renal transplantation. The Deflazacort Study Group. Pediatr Nephrol 14:682-688

19. Fine R, Stablein D, Cohen A, Tejani A, Kohaut E (2002) Recombinant human growth hormone post-renal transplantation in children: a randomized controlled study of the NAPRTCS. Kidney Int 62:688-696

20. Sanchez C, Kuizon BD, Goodman WG, Gales B, Ettenger RB, Boechat MI, Wang Y, Elashoff R, Salusky IB (2002) Growth hormone and the skeleton in pediatric renal allograft recipients. Pediatr Nephrol 17:322-328

21. Trompeter R, Filler G, Webb NJ, Watson AR, Milford DV, Tyden G, Grenda R, Janda J, Hughes D, Ehrich JH, Klare B, Zacchello G, Bjorn Brekke I, McGraw M, Perner F, Ghio L, Balzar E, Friman S, Gusmano R, Stolpe J (2002) Randomized trial of tacrolimus versus cyclosporin microemulsion in renal transplantation. Pediatr Nephrol 17:141-149

22. El Husseini A, El Agroudy A, El Sayed M, Sobh M, Ghoneim M (2004) Treatment of osteopenia and osteoporosis in renal transplant children and adolescents. Pediatr Transplant 8:357-361

23. Benfield M, Tejani A, Harmon W, McDonald R, Stablein DM, McIntosh M, Rose S, CCTPT Study Group (2005) A randomized multicenter trial of OKT3 mAbs induction compared with intravenous cyclosporine in pediatric renal transplantation. Pediatr Transplant 9:282-292

24. Grenda R, Watson A, Vondrak K, Webb NJ, Beattie J, Fitzpatrick M, Saleem MA, Trompeter R, Milford DV, Moghal NE, Hughes D, Perner F, Friman S, Van Damme-Lombaerts R, Janssen F (2006) A prospective, randomized, multicenter trial of tacrolimusbased therapy with or without basiliximab in pediatric renal transplantation. Am J Transplant 6:1666-1672

25. Smith J, Wong CS, Salamonik EB, Hacker BM, McDonald RA, Mancl LA, Williams BJ, Ibrahim A, Roberts FA (2006) Sonic tooth brushing reduces gingival overgrowth in renal transplant recipients. Pediatr Nephrol 21:1753-1759

26. Cransberg K, Cornelissen M, Lilien M, Van H, Davin J, Nauta J (2007) Maintenance immunosuppression with mycophenolate mofetil and corticosteroids in pediatric kidney transplantation: temporary benefit but not without risk. Transplantation 83:10411047 
27. Johnson C, Ahsan N, Gonwa T, Halloran P, Stegall M, Hardy M, Metzger R, Shield C 3rd, Rocher L, Scandling J, Sorensen J, Mulloy L, Light J, Corwin C, Danovitch G, Wachs M, van Veldhuisen P, Salm K, Tolzman D, Fitzsimmons WE (2000) Randomized trial of tacrolimus (Prograf) in combination with azathioprine or mycophenolate mofetil versus cyclosporine (Neoral) with mycophenolate mofetil after cadaveric kidney transplantation. Transplantation 69:834-841

28. Kahan B (2000) Efficacy of sirolimus compared with azathioprine for reduction of acute renal allograft rejection: a randomised multicenter study. Lancet 356:194-202

29. Legendre C, Norman D, Keating M, Maclaine G, Grant D (2000) Valaciclovir prophylaxis of cytomegalovirus infection and disease in renal transplantation: an economic evaluation. Transplantation 70:1463-1468

30. Antonopoulos I, Nahas W, Mazzucchi E, Ianhez L, Saldanha L, Arap S (2001) Comparison of palpation-guided and ultrasound-guided biopsies in transplanted kidneys. Clin Transplant 15:393-396

31. Henry M, Pelletier R, Elkhammas E, Bumgardner G, Davies E, Ferguson R (2001) A randomized prospective trial of OKT3 induction in the current immunosuppression era. Clin Transplant $15: 410-414$

32. Johnson R, Kreis H, Oberbauer R, Brattstrom C, Claesson K, Eris J (2001) Sirolimus allows early cyclosporine withdrawal in renal transplantation resulting in improved renal function and lower blood pressure. Transplantation 72:777-786

33. Kahan B, Kaplan B, Lorber M, Winkler M, Cambon N, Boger R (2001) RAD in de novo renal transplantation: comparison of three doses on the incidence and severity of acute rejection. Transplantation 71:1400-1406

34. MacDonald A (2001) A worldwide, phase III, randomized, controlled, safety and efficacy study of a sirolimus/cyclosporine regimen for prevention of acute rejection in recipients of primary mismatched renal allografts. Transplantation 71:271-280

35. Montagnino G, Tarantino A, Segoloni GP, Cambi V, Rizzo G, Altieri P, Castagneto M, Salvadori M, Cossu M, Pisani F, Carmellini M, Mastrangelo F, Ferrara R, Ponticelli C (2001) Long-term results of a randomized study comparing three immunosuppressive schedules with cyclosporine in cadaveric kidney transplantation. J Am Soc Nephrol 12:2163-2169

36. Zhang X, Ardissino G, Ghio L, Tirelli AS, Daccò V, Colombo D, Pace E, Testa S, Claris-Appiani A (2001) L-arginine supplementation in young renal allograft recipients with chronic transplant dysfunction. Clin Nephrol 55:453-459

37. Kumana C, Tong M, Li C, Lauder IJ, Lee JS, Kou M, Walley T, Haycox A, Chan TM (2003) Diltiazem co-treatment in renal transplant patients receiving microemulsion cyclosporin. Br J Clin Pharmacol 56:670-678

38. Ciancio G, Burke G, Gaynor JJ, Ruiz P, Roth D, Kupin W, Rosen A, Miller J (2006) A randomized long-term trial of tacrolimus/ sirolimus versus tacrolimus/mycophenolate versus cyclosporine/ sirolimus in renal transplantation: three-year analysis. Transplantation 81:845-852

39. El Dahshan K, Bakr M, Donia A, Badr A, Sobh M (2004) Coadministration of ketoconazole to tacrolimus-treated kidney transplant recipients: a prospective randomized study. Nephrol Dial Transplant 19:1613-1617

40. Machado P, Felipe CR, Hanzawa NM, Park SI, Garcia R, Alfieri F, Franco M, Silva HT Jr, Medina-Pestana JO (2004) An openlabel randomized trial of the safety and efficacy of sirolimus vs. azathioprine in living related renal allograft recipients receiving cyclosporine and prednisone. Clin Transplant 18:28-38

41. Nashan B, Curtis J, Ponticelli C, Mourad G, Jaffe J, Haas T (2004) Everolimus and reduced-exposure cyclosporine in de novo renal-transplant recipients: a three-year phase II, randomized, multicenter, open-label study. Transplantation 78:13321340

42. Lorber M, Mulgaonkar S, Butt KM, Elkhammas E, Mendez R, Rajagopalan PR, Kahan B, Sollinger H, Li Y, Cretin N, Tedesco H, B251 Study Group (2005) Everolimus versus mycophenolate mofetil in the prevention of rejection in de novo renal transplant recipients: a 3-year randomized, multicenter, phase III study. Transplantation 80:244-252

43. Gurkan A, Yakupoglu YK, Dinckan A, Erdogdu T, Tuncer M, Erdoğan O, Demirbas A, Akaydin M (2006) Comparing two ureter reimplantation techniques in kidney transplant recipients. Transpl Int 19:802-806

44. Silva H, Yang H, Abouljoud M, Kuo PC, Wisemandle K, Bhattacharya P, Dhadda S, Holman J, Fitzsimmons W, First MR (2007) One-year results with extended-release tacrolimus/MMF, tacrolimus/MMF and cyclosporine/MMF in de novo kidney transplant recipients. Am J Transplant 7:595-608

45. Moher D, Fortin P, Jadad AR, Jüni P, Klassen T, Le Lorier J, Liberati A, Linde K, Penna A (1996) Completeness of reporting of trials published in languages other than English: implications for the conduct of systematic reviews. Lancet 347:363-366

46. Budde K, Fritsche L (2005) Proposal for guidelines for publication of randomized trials in the American Journal of Transplantation. Am J Transplant 5:644-647

47. Martini S, Glander P, Fritsche L, Fleiner F, Budde K (2007) Suggested guidelines for reporting clinical results in transplantation trials. Transplant Rev 21:136-142 